\title{
High-Performance Cement Composite for Architectural Elements with Elimination of Micro Cracks
}

\author{
Lucia Osuská, Martin Ťažký, and Rudolf Hela
}

\begin{abstract}
Architectural concrete takes a prominent place in the design of not only the exteriors of modern buildings but also various additional interior and exterior elements that have an aesthetic function. The individual and own needs of the construction and its integration into the landscape are essential aspects that need to be taken into consideration when designing. Achieving a unique aesthetic appearance can be accomplished in several different ways, by using both special forms and changes in the composition of the concrete mixture itself. High-strength concrete is used very often in the manufacture of architectural parts and it is necessary to use cement composites with special properties for the manufacture of architectural elements, such as decorative linings, garden architecture or interior elements. Because of the high aesthetic requirements, the formation of micro cracks, which result primarily from the hydration of the cement and degrade the architectural aspect of the product, are very undesirable for these structural elements. The effort of many research groups or manufacturers of architectural concrete is to optimise production in such a way as to achieve the most significant reduction in this negative feature.

The objective of the experiment was to achieve a targeted reduction in the occurrence of these defects, which are mainly associated with volume changes during the hydration of the cement composite. In order to eliminate the negative shrinkage effect of concrete, special chemical additives will be examined in this document and their impact on the final physical and mechanical parameters of the composite will be verified. The most important observed property will be the shrinkage of concrete during maturation, which is the period immediately after mixing up to 28 days. Additional properties that point to the course and influence the hydration process itself will be also analyzed.
\end{abstract}

Index Terms-Architectural concrete elements, shrinkage of concrete, cement hydration, concrete curing, shrinkage cracks.

\section{INTRODUCTION}

In modern construction, architectural concrete is becoming increasingly popular with architects and designers, due to its extensive shaping possibilities. The elements of this modern and industrially acting material create the appearance of the exterior and the interior and are the result of an original architectural work. However, in order to achieve the desired

Manuscript received May 5, 2018; revised August 29, 2018. This work was supported in part by the Brno University of Technology department of Civil Engineering, Institute of Technology of Buildings Materials and Components. The theoretical background for the presented results was obtained with financial support from the project FAST-J-18-5374 'The issue of volumetric changes in high-performance concrete depends on different determination methods'.

The authors are with the Brno University of Technology department of Civil Engineering, Institute of technology of Buildings Materials and Components, Veveri 331/95, 60200 Brno, Czech Republic (e-mail: osuska.1@fce.vutbr.cz, tazky.m@fce.vutbr.cz, hela.r@fce.vutbr.cz). aesthetic appearance, it is necessary to approach the design of the concrete mixture carefully, as inappropriate procedures may have negative consequences that cause unattractiveness in the resulting work. One possible defect that disturbs the aesthetic appearance of the concrete is the occurrence of small cracks that result from the hydration of the cement. [1], [2] The presence of shrinkage cracks is not only unsightly but can also lead to a reduction in the durability of the concrete work. The shrinking process itself cannot be completely eliminated, but it can at least be partially restricted. [3] The cause of the shrinkage is a rather complex phenomenon and consists of several shrinking processes that are linked to each other to some extent. An initial volume change occurs due to the chemical reaction of cement with water, and further processes occur in the porous structure of the concrete. In addition to capillary effects, water loss is also active in the crystal lattice, and depending on the tension of water vapour in the environment, the moisture also migrates between the different sized capillaries. At the same time, stress due to the action of the cement stone acts on the surface of the aggregate. Due to capillary forces, the cement stone shrinks, and the surface of the aggregate grain is compressed. The most effective way to reduce the shrinkage process of concrete is most likely the appropriate choice of input materials and the use of so-called shrinkage reduction admixtures (SRA). These admixtures work on the principle of slowing the hydration of the cement by reducing the surface tension of water in the porous structure of the cement matrix. [4], [5] Three types of SRA were selected for this experiment and their influence on the behaviour of the cement composite and also on the properties of the cement pastes were examined.

\section{Methodology}

The objective of the experiment was to verify the influence of various SRA on volume changes in the concrete. In total, three types of SRA for concrete were used in different dosages. Especially, changes in the volume of the concrete were monitored within 28 days of normal maturation. This phenomenon was monitored using special U-profile equipment made of stainless steel, in which a test specimen was stored. The measuring trough that was used corresponds to the requirements of OENORM B 3329: 2009-06-01. [6] The movement of free head mould is influenced by volume changes using a highly sensitive electronic sensor that transfers and writes values to the software program. A further test was carried out to monitor the hydration processes by measuring the development of moisture temperatures using the semi-adiabatic method according to EN 196-9, and by determining the start and end of the cement curing time according to EN 196-3. [7][8] These properties, which show 
the course of the hydration procedures, are closely related to the final course of volume changes in concrete during its maturation. How these parameters are affected by the use of SRA and their dosing has been verified on cement pastes. To determination of development of hydration temperature were prepared cement pastes only. These cement pastes have the same composition ratio of binders and SRA as the produced concrete. Water cement ratio has been chosen to respect the same consistency verified according EN 1015-3. [9]

\section{A. Description and Composition of Raw Materials for the Production of Test Specimens}

Three types of additives were used for this experiment, all of which are active against the formation of shrinkage cracks in concrete. The additives that were used differed in their chemical base, the first type of additive was based on polyhydric alcohols (C40), the second type of additive was a combination of these polyhydric alcohols and surfactants (C60). The chemical base of the third additive (AD) was in the form of synthetic glycols. Their dosages were $0.5 \%$ and $2.0 \%$ of the weight of the cement. This dosage corresponds to the recommended dosage limit according to the manufacturer. In total, seven test mixtures were prepared. The amount of cement was chosen according to the design of high-strength architectural concrete in the amount of $450 \mathrm{~kg} / 1 \mathrm{~m} 3$. Because it is necessary to count with a greater amount of binder in architectural concrete design, this quantity has been sufficiently guaranteed a significant expression of shrinkage. The total amount of aggregate was calculated using the absolute volume equation and the percentage representation of individual fractions and is shown in Table 1. The consistency was designed in the range of 160-180 mm of cone seating according to EN 12350-2. [10] The amount of mixing water was determined in order to achieve the desired consistency and different amounts were compensated by the amount of aggregate in accordance with the absolute volume equation. The cement pastes contain the same ratio of binder base and chemical additives. Their water coefficient has been chosen in order to maintain the same degree of consistency from the spill method using the flow table according to EN 1015-3. [9]

TABLE I: COMPOSITION OF CONCRETE MIXTURES

\begin{tabular}{|c|c|c|c|c|c|c|c|}
\hline $\begin{array}{l}\text { Raw } \\
\text { materials }\end{array}$ & REF & $\begin{array}{l}\mathrm{C} 40 \\
0.5 \% \\
\end{array}$ & $\begin{array}{l}\mathrm{C} 40 \\
2.0 \% \\
\end{array}$ & $\begin{array}{l}\text { C60 } \\
0.5 \% \\
\end{array}$ & $\begin{array}{l}\text { C60 } \\
2.0 \% \\
\end{array}$ & $\begin{array}{l}\mathrm{AD} \\
0.5 \% \\
\end{array}$ & $\begin{array}{l}\mathrm{AD} \\
2.0 \% \\
\end{array}$ \\
\hline $\begin{array}{l}\text { Portl. cement } \\
\text { CEM I 42,5R }\end{array}$ & & & & $450 \mathrm{~kg}$ & & & \\
\hline $\begin{array}{l}\text { Water-cement } \\
\text { ratio w/c [-] }\end{array}$ & 0,39 & 0,39 & 0,36 & 0,39 & 0,36 & 0,39 & 0,36 \\
\hline $\begin{array}{l}\text { Fine } \\
\text { aggregate } 0-4 \\
\mathrm{~mm}\end{array}$ & & & & $48 \%$ & & & \\
\hline $\begin{array}{l}\text { Coarse } \\
\text { aggregate } 4-8 \\
\mathrm{~mm}\end{array}$ & & & & $10 \%$ & & & \\
\hline $\begin{array}{l}\text { Coarse } \\
\text { aggregate } \\
8-16 \mathrm{~mm}\end{array}$ & & & & $24 \%$ & & & \\
\hline $\begin{array}{l}\text { Coarse } \\
\text { aggregate } \\
11-22 \mathrm{~mm}\end{array}$ & & & & $18 \%$ & & & \\
\hline Plasticizer & & & & $1.0 \%$ & & & \\
\hline SRA [\%] & 0 & 0.5 & 2.0 & 0.5 & 2.0 & 0.5 & 2.0 \\
\hline
\end{tabular}

\section{RESULTS}

The following graph captures the development of hydration temperatures in the cement pastes. The measurements were performed using the semi-adiabatic method according to EN 196-9, where calorimeters were placed in the air conditioning chamber with constant ambient conditions of $20^{\circ} \mathrm{C}$ and a relative humidity of $50 \%$.

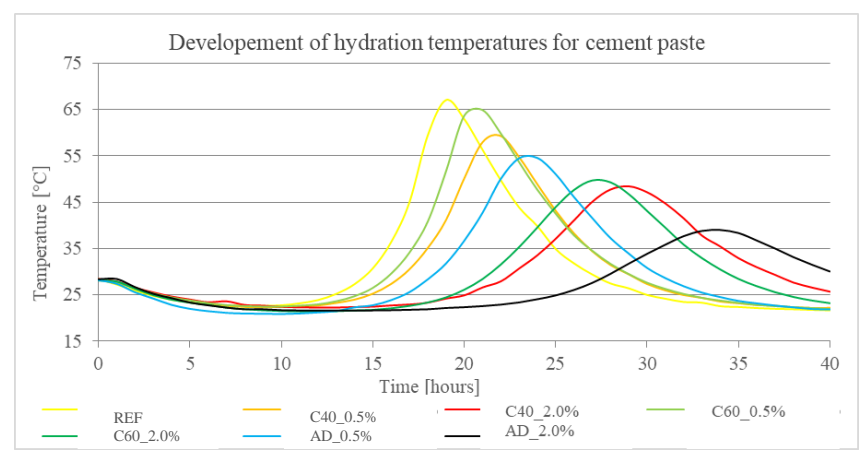

Fig. 1. Graphical evaluation of hydration temperature measurements.

The graphical course of the hydration temperatures of the cement pastes clearly indicates the effect of SRA during the hydration of the mixture. For all mixtures, it is noticeable that a higher dose of SRA significantly delays the course of hydration, and the overall maximum temperature drops. This fact will be further verified in the experiment by determining the curing start time and curing completion time of the same cement pastes.

Based on the course of the hydration temperatures of the cement pastes, it can be assumed that due to SRA, the course of the volume changes in the concrete mixtures will be strongly affected. Generally, the slower development of the hydration heat that is associated with a rapid drop in the maximum mixture temperature has a very positive effect on the prevention of micro cracks caused by the hydration process. There are no rapid volumetric changes in the concrete mixtures, which are normally caused by the migration of moisture within the element because of the rapid development of hydration heat, and the surfaces of such concrete elements will not be so susceptible to the formation of micro cracks, the creation of which leads to a deterioration of the whole architectural work.

TABLE II: DETERMINATION OF THE CURING START TIME AND CURING COMPLETION TIME

\begin{tabular}{lccccccc}
\hline \hline TIME & REF & $\begin{array}{l}\text { C40 } \\
0.5 \%\end{array}$ & $\begin{array}{l}\text { C40 } \\
2.0 \%\end{array}$ & $\begin{array}{l}\text { C60 } \\
0.5 \%\end{array}$ & $\begin{array}{l}\text { C60 } \\
2.0 \%\end{array}$ & $\begin{array}{l}\text { AD } \\
0.5 \%\end{array}$ & $\begin{array}{l}\text { AD } \\
2.0 \%\end{array}$ \\
\hline $\begin{array}{l}\text { The curing } \\
\text { start time }\end{array}$ & $12: 00$ & $12: 51$ & $15: 53$ & $12: 36$ & $14: 46$ & $13: 46$ & $16: 14$ \\
$\begin{array}{l}\text { The curing } \\
\text { completion } \\
\text { time }\end{array}$ & $15: 15$ & $15: 26$ & $17: 13$ & $15: 07$ & $15: 56$ & $15: 01$ & $17: 34$ \\
\hline \hline
\end{tabular}

The results of determining the curing start time and completion time of the analysed SRA cement pastes are shown above and these results directly correlate with the results of the course of the hydration temperatures. It is clear that the higher dose of SRA delays the start and completion 
times of the curing process of the cement paste and at the same time the differences between the various types of SRA are visible. In general, on the basis of both tests on the cement pastes, it can be assumed that the synthetic glycol-based AD additive is the most effective in terms of suppressing the rapid development of the hydration heat.

The subsequent graphical course of volumetric changes in the concrete mixtures highlight the real possibility of reducing these volume changes with SRA. Part of the evaluation of this test is also a visual comparison of the concrete mixture surface, especially in terms of the possible formation of micro cracks. Throughout the test, the test specimens were stored in a cellar room with almost constant ambient conditions of $20^{\circ} \mathrm{C}$ and a relative humidity of $70 \%$.

TABLE III: SHRINKAGE AT 36 AND 28 DAYS A COMPARISON OF SRA EFFICIENCY RELATIVE TO THE REFERENCE SAMPLE

\begin{tabular}{cccccccc}
\multicolumn{6}{c}{ EFFICIENCY RELATIVE TO THE REFERENCE SAMPLE } \\
\hline \hline \multirow{2}{*}{ TIME } & REF & C40 & C40 & C60 & C60 & AD & AD \\
& $0.5 \%$ & $2.0 \%$ & $0.5 \%$ & $2.0 \%$ & $0.5 \%$ & $2.0 \%$ \\
\hline 36 hours [\%] & -552. & -429. & -346. & -464. & -348. & -416. & -440. \\
& 07 & 23 & 07 & 63 & 66 & 57 & 68 \\
Comparison & - & $22 \%$ & $37 \%$ & $16 \%$ & $37 \%$ & $25 \%$ & $20 \%$ \\
with reference & & & & & & & \\
28 days [\%] & -751. & -628. & -470, & -646. & -496. & -579. & -552. \\
Comparison & 34 & 965 & 585 & 06 & 51 & 07 & 22 \\
with reference & - & $16 \%$ & $37 \%$ & $14 \%$ & $34 \%$ & $23 \%$ & $27 \%$ \\
\hline \hline
\end{tabular}

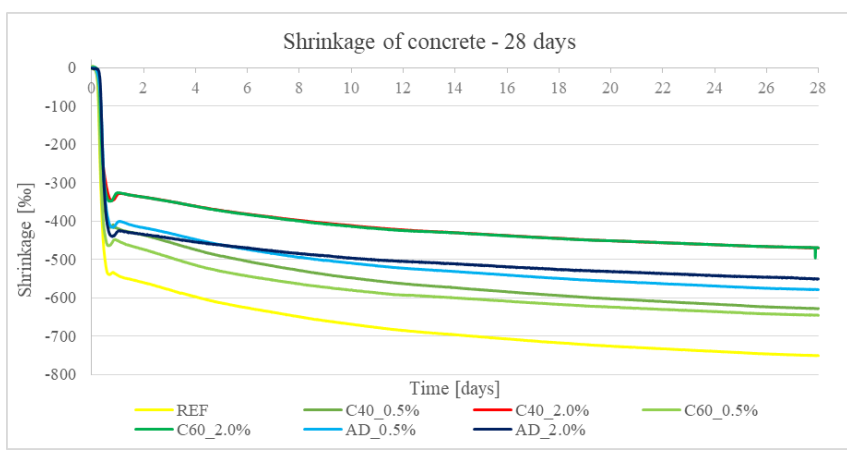

Fig. 2. Graphical evaluation of shrinkage of concrete.

From the graphical course of volumetric changes in the concrete mixes, it is clear that SRA have the greatest positive impact, especially on the initial shrinkage at 36 hours of maturation. Then, in the case of a lower percentage of dosing, the course of volumetric changes in all concrete mixtures with SRA is similar to that of the reference mixture. Another trend in the course of the volume changes at 28 days of maturation is shown by all SRA at their higher dosing. In this case, it is clear that volumetric changes after 36 hours of maturation have a more gradual progression than other mixtures.

The above-mentioned conclusions underline the results of the percentage comparison of the volume changes achieved in the given mixtures with the reference mixture. Regarding this, the additive $\mathrm{AD}$ at a dose of $0.5 \%$ and the additive $\mathrm{C} 40$ at a dose of $2.0 \%$ can be evaluated as the most effective. The highest positive value of the influence of the shrinkage effect compared to the reference mixture was $37 \%$. All of the results that were achieved largely correspond to the results of the analysis of the cement pastes. Furthermore, on the basis of the volume change course, it can be stated that the AD additive has the most positive behaviour in that its reduction in volume changes is not significantly dependent on its quantitative dosing. The opposite trend applies to the other two types of
SRA where there is a significant difference in the influence of the shrinkage at their different dosing levels. Due to lower SRA dosing, it is possible to avoid the negative effects that SRA can cause in terms of the resulting strength parameters of concrete, as evidenced by some studies. [4][5]

As expected, the resulting shrinkage values of the reference mixture were very significant after 28 days and exceeded the value of $0.750 \%$. With such significant shrinkage, the formation of micro cracks cannot be ruled out, which may not only result in deterioration of the mechanical and durability parameters of the concrete element but may also have an impact on its architectural aspect, for which cracking is completely undesirable. These micro cracks were also visually demonstrated only in the reference mixture, on the surface of the sample on which the volume changes were measured. Correct use of SRA therefore appears to be a very powerful tool in suppressing the formation of undesirable micro cracks on the surface of a concrete architectural work whose shape is often very subtle, therefore high-performance concrete must be used for the production of such works.

\section{CONCLUSION}

As part of the experiment, the influence of different types of SRA and their quantity dosing on the hydration process of the cement matrix and especially on the volume changes of concrete mixtures were assessed. The results clearly demonstrate that SRA strongly influence the hydration process itself, which has a positive influence on the resulting volume changes. Therefore, SRA appear to be very effective tools for eliminating the frequent occurrence of micro-defects in architectural concrete, where the emphasis is placed on a quality surface. For the production of demanding architectural elements, it is often necessary to use high-performance concrete with a higher dose of the binding component. This has a negative impact on the resulting volume changes and the associated formation of micro cracks on the surface of the element and thus leads to the degradation of the entire work. SRA are one of the ways to prevent these negative effects on architectural concrete.

\section{REFERENCES}

[1] M. I. Serralheiro, J. Brito, and A. Silva, "Methodology for service life prediction of architectural concrete facades," Construction and Building Materials, vol. 133, pp. 261-274, 2017.

[2] A. M. Matos, L. Maia, S. Nunes, and P. Milheiro-Oliveira, "Design of self-compacting high-performance concrete: Study of mortar phase," Construction and Building Materials, vol. 167, pp. 617-630, 2018.

[3] L. OsuskÁ and R. Hela, "Use of fluidized bed combustion fly ash as addition reducing shrinkage of concrete," Binders, Materials and Technologies in Modern Construction II, pp. 141-144, 2016.

[4] D. Y. Yoo, N. Banthia, and Y. S. Yoon, "Effectiveness of shrinkage-reducing admixture in reducing autogenous shrinkage stress of ultra-high-performance fiber-reinforced concrete," Cement and Concrete Composites, vol. 64, pp. 27-36, 2015.

[5] S. H. Kang, S. G. Hong, and J. Moon, "Shrinkage characteristics of heat-treated ultra-high-performance concrete and its mitigation using superabsorbent polymer based internal curing method," Cement and Concrete Composites, vol. 89, 2018.

[6] Oenorm B 3329:2009-06-01 Vergussmörtel - Anforderungen und Prüfmethoden, 2009

[7] EN 196-9 Methods of testing cement - Part 9: Heat of hydration Semi-adiabatic method, 2010

[8] EN 196-3 Methods of testing cement - Part 3: Determination of setting times and soundness, 2016

[9] EN 1015-3 Methods of test for mortar for masonry - Part 3: Determination of consistence of fresh mortar (by flow table), 1999. 
[10] EN 12350-2 Testing fresh concrete - Part 2: Slump-test, 2009.

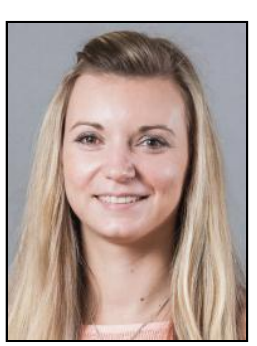

Lucia Osuská was born in Myjava, Slovak Republic on 10th of October 1990. In 2016 she graduated Brno University of Technology, Civil Engineering - Institute of Technology and Buildings Materials and Composites and she get a title Ing. At the present time she continues a study as an Ph.D. candidate.

During her study she was participate of an internship in CEMEX Reserch Group in Switzerland, were she worked as a researcher. At the present time she works at AdMas Center (Advanced
Materials, Structures and Technologies Institute https://admas.eu/en/) as a researcher. She published at many domestic and foreign conference indexed by SCOPUS and other important periodic. Her background is technology of concrete and silicates composites. Her specialization are the volumetric changes of concrete and the development of high-performance concrete. She cooperates with foreign students in exchange programs such as ERASMUS, FREE MOVERS or UNIGOU. the top left of the biography. 